\title{
Measuring Limits of Arbitrage in Fixed-Income Markets
}

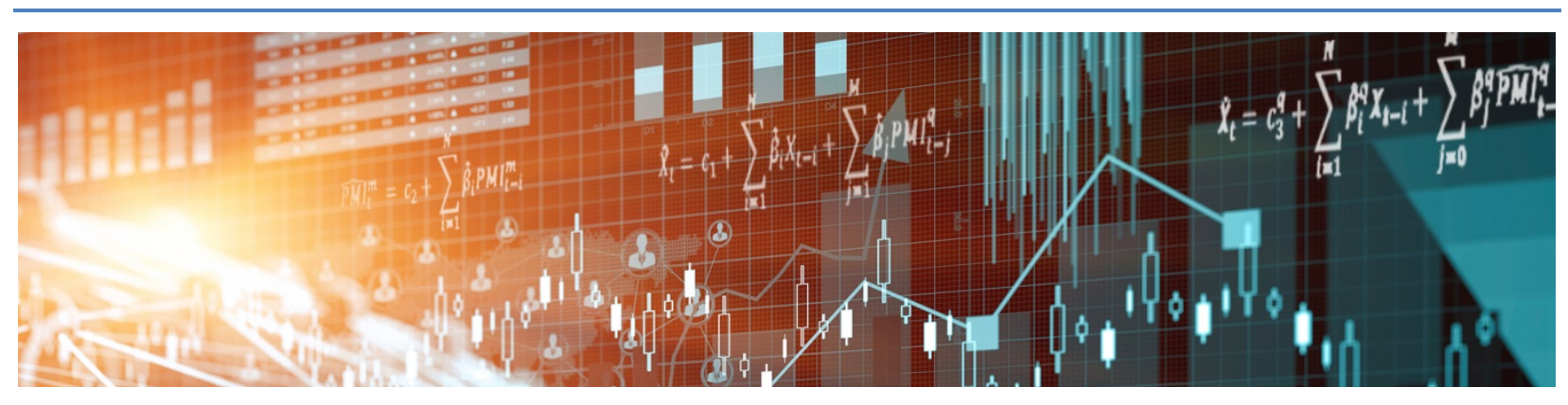

by Jean-Sébastien Fontaine and Guillaume Nolin 
Bank of Canada Staff Working Paper 2017-44

October 2017

\section{Measuring Limits of Arbitrage in Fixed-Income Markets}

by

Jean-Sébastien Fontaine and Guillaume Nolin

Financial Markets Department

Bank of Canada

Ottawa, Ontario, Canada K1A 0G9

jsfontaine@bankofcanada.ca

gnolin@bankofcanada.ca 


\section{Acknowledgements}

We thank Bruce Chen, Jens Christensen, Darrell Duffie, Bruno Feunou, Meredith FraserOhman, Étienne Giroux-Léveillé, Toni Gravelle, Sermin Gungor, Madhu Kalimipalli, Natasha Khan, Gitanjali Kumar, Stéphane Lavoie, James Pinnington, Francisco Rivadeneyra, Adrien Verdhelan, Harri Vikstedt, Jun Yang, Jing Yang and Bo Young Chang for comments suggestions. We also thank James Pinnington for invaluable research assistance. 


\begin{abstract}
We use relative value to measure limits to arbitrage in fixed-income markets. Relative value captures apparent deviations from no-arbitrage relationships. It is simple, intuitive and can be computed model-free for any bond. A pseudo-trading strategy based on relative value generates higher returns than one based on the well-known noise measure. The relative value is therefore a better proxy for limits to arbitrage. We construct relative value indices for the US, UK, Japan, Germany, Italy, France, Switzerland and Canada. Limits to arbitrage increase with the scarcity of capital: we find that each index is correlated with local volatility and funding costs. Limits to arbitrage also exhibit strong commonality across countries, consistent with the international mobility of capital. The relative value indices are updated regularly and available publicly.
\end{abstract}

Bank topics: Asset pricing; Financial markets; International financial markets JEL code: G12

\title{
Résumé
}

Nous utilisons la valeur relative pour mesurer les limites à l'arbitrage sur titres à revenu fixe. La valeur relative rend compte des écarts apparents par rapport aux relations de nonarbitrage. Il s'agit d'une valeur simple, intuitive et calculable sans le recours à un modèle, quelle que soit l'obligation. Une stratégie de pseudo-négociation se fondant sur la valeur relative génère des rendements plus élevés que celle qui s'appuie sur la mesure bien connue du bruit statistique. La valeur relative est donc un meilleur indicateur des limites à l'arbitrage. Nous élaborons des indices de valeur relative pour les États-Unis, le Royaume-Uni, le Japon, l'Allemagne, l'Italie, la France, la Suisse et le Canada. Les limites à l'arbitrage augmentent avec la rareté du capital dans chacun des pays. Elles présentent aussi de fortes similitudes entre les pays, ce qui cadre avec la mobilité des capitaux dans le monde. Les indices de valeur relative sont mis à jour régulièrement et rendus publics.

Sujets : Évaluation des actifs; Marchés financiers; Marchés financiers internationaux Code JEL : G12 


\section{Non-Technical Summary}

Bonds emitted by the same issuer with the same cash flows should have the same prices and yields. This is the law of one price. In practice, however, deviations from the law of one price are pervasive in the bond market. For example, at the height of the global financial crisis, the difference in yields between very similar bonds issued by the US Treasury exceeded 100 basis points. Such a large difference can persist for extended periods of time, even in normal times, despite the fact that it should be perceived as a golden opportunity for arbitrageurs. This points to the existence of limits to arbitrage in fixedincome markets.

In this paper, we propose a new, simple, intuititive and non-parametric measure of limits to arbitrage in fixed-income markets. This relative value measure is built to mimic the strategy an arbitrageur would adopt. An expensive bond would be shorted, while a cheap bond would be purchased. To hedge interest rate risk, arbitrageurs would take an opposite position in a portfolio of bonds with the same duration, convexity and par value. Relative value is simply the difference in price between the targeted bond and this replicating portfolio.

We show that using relative value as a trading signal for a pseudo-trading strategy produces significant excess returns. This stands in contrast to trading measures based on parametric yield curve models, which are shown to produce a large number of false-positive signals that generate small negative returns. This shows that the noise index, a wellknown measure of limits to arbitrage based on a parametric yield curve, includes a large share of statistical noise.

We make available aggregate indices of relative value to sovereign issuers in eight countries: Canada, France, Germany, Italy, Japan, Switzerland, the United Kingdom and the United States. We show that a large share of variations in individual relative value is driven by a single factor. We also show that indices are highly correlated internationally for Canada, Germany, Switzerland, the UK and the US, while those of France and Italy are related to each other. Finally, we show that these indices are highly correlated with local measures of stress in bank funding markets and equity market volatility. 


\section{Introduction}

Bonds from the same issuer and with the same cash flows should have the same prices. This is the law of one price. But deviations from the law of one price are pervasive in the bond market in practice. Panels (A) and (B) of Figure 1 show the yields to maturity of all United States Treasury bonds for a day in 2008 and in 2014, respectively. Deviations can be large — as in 2008 - or they can be small — as in 2014 - but they are rarely absent.

The most common strategy to exploit these deviations is the so-called relative value trade. Relative value is based on the idea that bonds with the same risk should have the same expected returns. For instance, a relative value trade may involve a portfolio of bonds replicating the duration and convexity of the target bond. This is different than replicating the cash flows, since exact replication of a coupon bond is typically much costlier. ${ }^{1}$ But relative value trading does not always eliminate these deviations. Instead, these persistent deviations reveal limits of arbitrage due to funding market frictions and bond market segmentations (Duffie, 1996; Vayanos and Weill, 2008; Vayanos and Vila, 2009). ${ }^{2}$ The profit motive of arbitrageurs can reduce deviations when funding constraints are loose and when arbitrage capital is abundant, as in 2014. Conversely, deviations will be larger and more persistent when funding constraints are tight and arbitrage capital is scarce, as in 2008.

These deviations from arbitrage relationships reveal valuable information. For instance, Longstaff (2004) uses bonds issued by the Resolution Funding Corporation (Refcorp), which are guaranteed by the US Treasury, to document the flight-toliquidity premium in Treasury bond prices. Using a dynamic model, Fontaine and

\footnotetext{
${ }^{1}$ Replicating the cash flows of a coupon bond would involve extensive trading in the relatively illiquid market for stripped securities.

${ }^{2}$ Note that accounting for direct transaction costs does not eliminate deviations (e.g., Amihud and Mendelson 1991). See Fontaine and Garcia (2015) for a review.
} 
Garcia (2012) show that an index of liquidity premia across US Treasury bonds can predict excess bond returns across a wide range of fixed-income markets. Using a static parametric yield curve, Hu, Pan and Wang (2013) (HPW thereafter) show that an index of fitting errors - the "noise" measure - is priced in the cross-section of returns from hedge funds and carry trades. In other words, aggregating these deviations tends to reveal an important financial risk factor.

We introduce a new measure of deviations based on the relative value of bonds. This measure is model-free, bypassing the need for preliminary parameter estimation. It is intuitive and easy to compute. For any bond in our sample, we use a small number of comparable bonds to form a replicating portfolio with the same duration and convexity. This bond and its replicating portfolio should have the same expected return. The relative value for that bond is the difference between its yield and that of the replicating portfolio.

Existing approaches to measure these deviations rely on parametric models, of which HPW's noise index is arguably the most popular. For this class of measures, preliminary estimates must be obtained for the parameters of a factor yield curve model to derive an index of fitting errors (relative to curve). Parameter estimation introduces a layer of complexity. It also introduces sampling uncertainty and potential model misspecification. In itself, the large variety of curve-fitting methods actively used by practitioners suggests a certain level of arbitrariness in the estimation process (Bliss, 1996; Ron, 2000).

In the first part of the paper, we compare relative value with HPW's measure. Our criterion to compare these measures is their economic value when used as a signal to implement a pseudo-trading strategy that doesn't take into account the limits of arbitrage. The returns from trading on this signal correspond to the profits of risk-averse investors carrying risky convergence trades between bonds (Liu and Longstaff, 2004; 
Fontaine and Garcia, 2015). Higher returns from pseudo-trading strategies mean arbitrageurs face greater costs or greater risk when implementing these strategies. Thus, a measure capable of identifying deviations from limits of arbitrage should generate positive returns over time. The persistent returns of a pseudo-trading strategy based on relative value thus validate the measure's ability to identify limits of arbitrage. On the other hand, a strategy based on HPW's measure generates significantly lower returns and signals a large number of ultimately unprofitable trades; it is therefore an inferior gauge of limits of arbitrage.

Specifically, we compute relative value and HPW's noise measure every day and for each bond and use them as trading signals. Once a bond's signal exceeds a predetermined threshold, our strategy enters a convergence trade that carries no interest rate risk (similar to Duarte et al. (2007)). The trade is exited when the signal falls to zero or when the duration of the trade exceeds a calendar year. We aggregate profits and losses across convergence trades to compute monthly returns. In the US Treasury bond market, relative value produces an average monthly return of $0.52 \%$ between 1988 and 2017. By contrast, the noise measure produces an average return of $0.16 \%$. Repeating this comparison between 2005 and 2017 in the US, UK, Japan, Germany, Italy, France and Canada produces similar results. Switzerland stands as the only exception. Overall, the results show that relative value is a better measure of funding constraints and capital scarcity faced by arbitrageurs.

Further diagnostics reveal that using HPW's noise measure produces a large share of trades that generate small but negative returns, with low variance and that are largely uncorrelated with returns from other trades. These trades constitute between one-third and two-thirds of positive trade signals, depending on the sovereign issuer and sample period. These false-positive signals are generated by fitting errors in the yield curve estimation process and are not associated with significant deviations from 
arbitrage relationships. Establishing a convergence trade in these cases generates small negative returns, notably because of transaction costs. The variance is low because the prices of neighbouring bonds are essentially in line and because the trade is exited when the fitting errors vanish. Aggregating noise trades produces a portfolio that produces low returns and low variance, since fitting errors are uncorrelated.

In the second part of the paper, we propose an aggregate relative value index similar to the one created by HPW and compute it for several large sovereign issuers. Higher values for the index indicate that deviations from arbitrage relationships are larger on average (in absolute value). These indices are available publicly and updated regularly on the Bank of Canada's website. We find that the index is highly correlated with local volatility indices (such as the VIX). This is consistent with the mechanism whereby higher systematic volatility raises the scarcity of arbitrage capital. We also find that a country-specific relative value index is typically correlated with a local version of the spread between the overnight index swap (OIS) and the interbank lending market rates. This is consistent with the mechanism whereby higher funding costs raise limits of arbitrage. In line with results in Malkhozov et al. (2016), we find that the index for the US, UK, Canada, Germany and Switzerland are highly correlated. By contrast, the relative value index for the bond market in France and Italy diverged from that of other countries during the euro area sovereign crisis. The case of the bond market in Japan appears to be largely idiosyncratic.

This paper is structured as follows. Section 1 presents the data and details how relative value is measured for individual bonds. Section 2 compares the performance of relative value and the noise measure as signals for pseudo-trading strategies. Section 3 describes the construction of the relative value index and presents an analysis of the results for large sovereign issuers. 


\section{Data and Methodology}

\subsection{Data}

We use end-of-day clean prices and yields to maturity for US, British, Canadian, French, German, Italian, Japanese and Swiss government bonds. For the US, we use prices and yields of Treasury bonds data between 1987 and March 2017, taken from the Center for Research in Security Prices database (CRSP). Before 1987, the different tax treatments of coupon and principal payments affected the relative valuation of bonds. ${ }^{3}$

For Canada, we use daily prices between 1994 and March 2017, taken from StatPro before April 2009 and from FTSE TMX (formerly PC-Bond and DEX) thereafter. Similar to the US, coupon and capital gains had different tax treatments before 1994. For bonds issued by the British, French, German, Italian, Japanese and Swiss governments, we use daily data from Bloomberg and Markit Evaluated Bonds between 2005 and March 2017.

Following HPW, we impose the following filters. For every country, we use bonds with time remaining to maturity between 1 and 10 years and we exclude inflationlinked bonds, variable-rate bonds and bonds with embedded options. Other restrictions and filters are described in the Appendix. Table 1 reports the number of observations for each country as well as summary statistics for the number of bonds available on any given day. Japan and the US stand out with having the largest number of bonds, while Switzerland stands out with the lowest number. To compute excess returns, we obtain the overnight interest rates from Bloomberg. ${ }^{4}$

\footnotetext{
${ }^{3}$ In the US, equal tax treatment of coupon and principal payments was introduced in the Tax Reform Act of 1986. Before that, tax deductions for coupon payments made higher coupon bonds dearer. See Green and Ødegaard (1997) for a complete discussion. In Canada, the lifetime capital gains deduction was eliminated for property acquired after February 22nd, 1994. Before this date, tax deductions for the principal payment made higher coupon bonds cheaper.

${ }^{4}$ For the US, we use the effective Federal funds rate if available. Otherwise, we use the mid-point
} 


\subsection{Methodology}

The measure of relative value proposed in this article is model-free. It is based on the butterfly bond-trading strategy, used by market participants to profit from deviations of the price of a bond from the valuation of other similar bonds. This butterfly strategy is a portfolio of bonds combining a position in the target bond and an opposite position in bonds of similar duration. This opposite position typically combines two bonds: one with a slightly lower duration and another with a slightly higher duration. This configuration of bonds on each side of the target bond could be thought of as the wings of the butterfly.

In our methodology, the wings are chosen to match the duration, convexity and par value of the target. Matching these three characteristics of the target bond requires three other bonds. This portfolio essentially replicates the risk of the target bond. Assuming the absence of arbitrage, the target bond and the replicating portfolio should have the same expected return: they carry the same interest rate risk and the same default risk (if any).

However, a difference in yields may not be a pure arbitrage opportunity. An arbitrage would be available only if investors can profit from this deviation using risk-free and self-financing trading strategies. Hence, the relative value of a bond with respect to its replicating portfolio is a proxy for limits that prevents arbitrageurs from driving these deviations to zero. These frictions can affect the ability to borrow funds or bonds in the repo market (Duffie, 1996).

of the Federal Reserve official target range when available. For Canada, we use the Bank of Canada target rate. For the UK, we use the Bank of England's official Bank rate. For euro area countries, we use the European Central Bank's main refinancing operation rate. For Switzerland, we use the Swiss National Bank's official London Interbank Offered (LIBOR) target. For Japan, we use the Bank of Japan's policy rate. 


\subsection{Calculating Portfolio Weights}

We construct the replicating portfolio using three bonds from the same issuer. To select these bonds, we sort outstanding bonds by duration. The first two bonds are the ones preceding and following the target on the duration axis. We choose the third bond from the remaining bonds on the same side as the bond with the duration closest to the target's. This choice brings the replicating bonds' average duration closer to the target's.

We label the target bond $b$ and label the replicating bonds with $i=1,2,3$. The duration and convexity of the bonds are denoted by $d_{i}$ and $c_{i}$ respectively. We compute modified duration and convexity using mid yields. The weights $w_{i}$ as a fraction of par value are chosen to satisfy:

$$
\begin{aligned}
& d_{1} w_{1}+d_{2} w_{2}+d_{3} w_{3}=w_{b} d_{b} \\
& c_{1} w_{1}+c_{2} w_{2}+c_{3} w_{3}=w_{b} c_{b} \\
& w_{1}+w_{2}+w_{3}=w_{b}=1 .
\end{aligned}
$$

Equation 1 means that the duration of the replicating portfolio and that of the target are the same. Equation 2 means that the convexities of the target and the replicating portfolio are the same. Equation 3 means that the target bond and the replicating portfolio have the same par value. Without loss of generality, we normalize the weight $w_{b}$ to 1 .

To eliminate extreme portfolio weights, we impose the following conditions on the weights:

$$
0 \leq w_{i} \leq 2 / 3 \quad \forall i \in\{1,2,3\}
$$

Non-negative weights prevent the replicating portfolio from including a mixture of 
short and long positions. Weights inferior to two-thirds guarantee that the relative value incorporates information from the prices of several neighbouring bonds. The system defined by Equations (1-3) may have no solution if the inequality in Equation 4 is binding. In this case, we relax the equality constraint in Equation 2. Instead, we minimize the difference in convexity between the target and the replicating portfolio:

$$
\underset{w_{1}, w_{2}, w_{3}}{\operatorname{argmin}}\left(c_{1} w_{1}+c_{2} w_{2}+c_{3} w_{3}-c_{b}\right)
$$

subject to Equations 1, 3 and $4 .^{5}$

\subsection{Measurement of Relative Value}

Given the weights $w_{1}, w_{2}, w_{3}$, we compute the yield to maturity of the replicating portfolio matching the duration and convexity of the target. Given the bid, mid and ask yields $y_{i t}^{b i d}, y_{i t}^{m i d}$ and $y_{i t}^{a s k}$ of bond $i$ at time $t$, the yield of the replicating portfolio is given by

$$
\begin{aligned}
& \ddot{y}_{t}^{b i d}=y_{1 t}^{b i d} w_{1}+y_{2 t}^{b i d} w_{2}+y_{3 t}^{b i d} w_{3} \\
& \ddot{y}_{t}^{m i d}=y_{1 t}^{m i d} w_{1}+y_{2 t}^{m i d} w_{2}+y_{3 t}^{m i d} w_{3} \\
& \ddot{y}_{t}^{a s k}=y_{1 t}^{a s k} w_{1}+y_{2 t}^{a s k} w_{2}+y_{3 t}^{a s k} w_{3},
\end{aligned}
$$

where $\ddot{y}_{t}^{b i d}$ and $\ddot{y}_{t}^{a s k}$ correspond to the yields to maturity when buying or selling the replicating portfolio bonds, accounting for transaction costs. When the observed yield for the target is higher than that of the replicating portfolio, the profitable strategy is to buy the target and short the replicating portfolio. The opposite strategy is profitable when the observed yield for the target is lower than that of the replicating

\footnotetext{
${ }^{5}$ We use the lsqlin function with the active-set algorithm in MATLAB to solve our constrained linear least-squares problem. Our initial point for the solution process is a vector of equal weights $(1 / 3)$.
} 
portfolio.

We define

$$
\begin{aligned}
& r v_{b t}^{+}=-y_{b t}^{b i d}+\ddot{y}_{t}^{a s k} \\
& r v_{b t}^{-}=y_{b t}^{a s k}-\ddot{y}_{t}^{b i d}
\end{aligned}
$$

When the target bond is expensive relative to its replicating portfolio, its relative value is $r v_{b t}^{+}$. When the target bond is cheap relative to its replicating portfolio, its relative value is $r v_{b t}^{-}$. Note that $r v_{b t}^{+}$and $r v_{b t}^{-}$cannot be strictly positive at the same time. The target cannot be simultaneously expensive and cheap relative to its replicating portfolio. However, $r v_{b t}^{+}$and $r v_{b t}^{-}$can be negative at the same time because of the bid-ask spread. In this case, $r v_{b t}$ is set to zero since, in this case, the absence of arbitrage holds once we account for transaction costs. The relative value of a given target bond $b$ is defined as:

$$
r v_{b t} \equiv\left\{\begin{array}{lll}
r v_{b t}^{+} & \text {if } \quad r v_{b t}^{+}>0 \\
0 & \text { if } \quad r v_{b t}^{+}<0 \text { and } r v_{b t}^{-}<0 \\
-r v_{b t}^{-} & \text {if } \quad r v_{b t}^{-}>0,
\end{array}\right.
$$

where we use the negative $-r v_{b t}^{-}$, which means that $r v_{b t}$ takes a negative value when the target is relatively cheap. An alternative definition simply uses mid yields:

$$
\tilde{r v}_{b t}=-y_{b t}^{m i d}+\ddot{y}_{t}^{m i d}
$$

This definition produces larger relative values than our benchmark case and overstates the presence of limits of arbitrage. 


\subsection{The Relative Value Index}

We aggregate the relative values of all bonds to produce a relative value index of a given issuer. This aggregation is similar to that underlying HPW's noise index. The relative value index $r v_{t}$ is given by the root mean square of the individual relative values $r v_{b t}$ :

$$
r v_{t}=\sqrt{\frac{1}{N_{t}} \sum_{b=1}^{N_{t}} r v_{b t}^{2}},
$$

where $N_{t}$ is the number of outstanding securities of the same issuer and with a remaining time to maturity of between 1 and 10 years at time $t$. When computing the dispersion index, we exclude bonds with a relative value greater than four times the sample standard deviation. HPW implements the same filter.

\section{Relative Value as a Trading Signal}

This section assesses the economic value of relative value and of the noise measure. The results show that relative value provides a better signal than the noise measure when used to implement pseudo-trading strategies. These are pseudo-trading strategies, since they may not be profitable in a realistic setting, after accounting for funding costs and the costs of borrowing bonds to sell short. These may prevent most investors from entering these trades profitably. Further, capital available to implement these strategies may be scarce. But this is a feature and not a bug, since the objective of our methodology is to measure limits of arbitrage. Trading profits from the quasi-arbitrage strategy demonstrate that deviations from arbitrage relationships are persistent and fluctuate over time.

The returns from these strategies can be volatile. A strategy that benefits from bond mispricing is essentially a bet that limits of arbitrage will diminish. A "good" 
signal is expected to underperform when limits of arbitrage increase; for example, during a period of worsening funding conditions or capital availability. It is the longterm profitability of these trading strategies that provides the relevant measure of economic value. Indeed, Duarte et al. (2007) show that these strategies amount to more than "picking up nickels in front of a steamroller."

\subsection{Implementing the Trading Strategy}

We use relative value or the noise measure to decide whether to implement our trading strategy. Every day, we consider bonds with a remaining time to maturity of between 1 and 10 years. For each measure, we construct a portfolio of trades and we track the performance of each portfolio over time.

For relative value, we include a new trade when its relative value (calculated with mid yields) is greater than \pm 5 basis points (bps). ${ }^{6}$ If a bond appears relatively expensive, a butterfly strategy is implemented, with one unit of the target bond sold short and the purchase of long positions in the replicating portfolio, with weights given by Equations 1 to 4 . The strategy is inverted when a bond appears cheap. Following Duarte et al. (2007), positions are held until convergence; that is, when the signal reaches 0 bps. $^{7}$ All positions are liquidated after at most one year or at the end of the sample period. We do not include a new trade when the target bond is already part of the portfolio; this position must be liquidated before this bond can be considered again for this portfolio.

We repeat the same procedure for HPW's noise measure. The noise measure for an individual bond is given by $\epsilon_{b t} \equiv \tilde{y}_{b t}-y_{b t}$ where $\tilde{y}_{b t}$ is the mid yield to maturity

\footnotetext{
${ }^{6}$ Trades are initiated when there are more than 5 days of prices on the target bond and each of the constituents of the replicating portfolio. Results are robust when using a \pm 10 bps threshold.

${ }^{7}$ Trades are also liquidated at the end of the sample period, on the last day of price availability for the target bond and each of the constituents of the replicating portfolio, and when the target bond has less than 3 months remaining until maturity (as bond prices become increasingly unreliable close to maturity).
} 
implied by a curve estimated using the Svensson (1994) model. ${ }^{8}$ We estimate the parametric curve daily for each country. Trades are initiated when the noise measure for a given bond is greater than \pm 5 bps.

\subsection{Computing Returns}

Each trade initially has zero duration and zero convexity and thus carries little interest rate risk. To minimize transaction costs, we do not continually adjust portfolio weights, since the duration and convexity drifts are small. However, the computation of returns must account for the cost of carrying each trade. The costs of carry vary over time and across trades (either positive or negative) because of the initial investment as well as differences between coupon payments.

To compute returns, it is useful to think of a specialized fund implementing our strategy for a single bond. The equity value $E_{t}$ of this fund at time $t$ is given by

$$
E_{t}=E_{0}+B_{t}+P_{t}
$$

where $E_{0}$ is the initial equity or margin set aside to cover for potential losses; $B_{t}$ is the fund's borrowing, including the initial cash outlay, coupon payments and interest earned or paid; and $P_{t}$ is the marked-to-market value of the bonds bought or sold short for this strategy, accounting for the bid-ask spread.

Duarte et al. (2007) choose the initial equity $E_{0}$ such that the sample volatility of returns is $10 \%$ on average across funds. In our sample, $E_{0}=10$ yields a volatility slightly below $10 \%$. For simplicity, we choose $E_{0}=10$. We also checked that setting the $E_{0}=10$ is enough to cover any loss recorded in our sample. The evolution of net

\footnotetext{
${ }^{8}$ We also use Grkaynak et al. (2007) parameter estimates for from the Federal Reserve Board's website, at http://www.federalreserve.gov/pubs/feds/2006/200628/200628abs.html. The results are similar.
} 
borrowing $B_{t}$ is given by:

$$
B_{t+1}=B_{t}\left(1+r f_{t}\right)+C_{t+1}
$$

where $B_{0}=P_{0}$ is the initial cash outlay, $r f_{t}$ is the borrowing rate, and $C_{t+1}$ are subsequent coupon payments. ${ }^{9}$ The marked-to-market value $P_{t}$ is computed as if the positions were liquidated at end-of-day bid and ask prices, accounting for accrued interest.

Given the evolution of the equity value for a given fund $E_{i, t}$, the daily returns $R_{i, t+1}$ between $t$ and $t+1$ is given by

$$
R_{i, t+1}=\frac{E_{i, t+1}}{E_{i, t}}-1
$$

Following Duarte et al. (2007), for each signal we create an equally weighted portfolio of funds trading individual bonds. The return for the portfolio is the equally weighted average of returns across funds. If no fund is active on a given day, the index return for that day is zero. We then construct an index of arbitrage excess returns based on each signal. The index returns $\bar{R}_{t}$ across all funds on day $t$ is given by:

$$
\begin{aligned}
& \bar{R}_{t+1}=\frac{1}{I} \sum_{i}^{I} R_{s t+1} \quad \text { if } I>1 \\
& \bar{R}_{t+1}=0 \quad \text { if } I=0 .
\end{aligned}
$$

For convenience, the initial index value is set to $V_{0}=100$. At time $t+1$, the

\footnotetext{
${ }^{9}$ We use the Actual/360 basis to calculate the daily interest paid. For simplicity, we use the policy interest rate in each country when computing the cost of borrowing. In the US, we use the effective Fed funds rate if available. Otherwise, we use the mid-point of the Federal Reserve official target range when available. For Canada, we use the Bank of Canada target rate. For the UK, we use the Bank of England's official Bank rate. For euro area countries, we use the European Central Bank's main refinancing operation rate. For Switzerland, we use the Swiss National Bank's official LIBOR target. For Japan, we use the Bank of Japan's policy rate.
} 
arbitrage index is simply $V_{t+1}=V_{t} \times\left(1+\bar{R}_{t+1}\right)$. The index can be interpreted as equally weighted investments across funds that are rebalanced daily.

\subsection{Trade Convergence}

This section compares the performance of these trade portfolios for US Treasuries since 1988. Panel (A) of Figure 2 shows the distribution of autocorrelations across bonds in our sample for each measure, respectively. The average autocorrelation of each measure is around 0.6 and the distributions are similar. ${ }^{10}$ Both trading signals are mean-reverting, which is consistent with bond arbitrage strategies converging over time. Panel (B) of Figure 2 reports the histogram of duration across all trades in the US. Most trades are short-lived and liquidated within 30 days. A larger number of trades based on the noise measure are liquidated at the end of one year, without having converged. Overall, trades based on relative value converge faster and have higher mean reversion.

\subsection{Evaluating Economic Value}

Panel (A) of Figure 3 shows the histograms of total gains or losses across all relative value and noise trades, respectively. Using the noise measure produces a much higher number of trades with returns that are close to zero but negative. By contrast, using relative value produces a larger number of trades with positive returns. Panel (B) reports the histograms for the variance of daily trade returns, showing that the noise measure produces a large number of trades with very low variance.

The means and variances are correlated in the cross-section of trades. This is shown in Figure 4, which reveals the joint distribution of means and variances in our sample. The contour map reports the number of trades for each square on a

\footnotetext{
${ }^{10}$ We compute the autocorrelation estimates for each measure before accounting for the bid-ask spread.
} 
grid defined by the mean and standard deviation of daily trade returns. Panels (A) and (B) show this contour map for trades using the noise measure in the long and short sample, respectively. The results show that the noise measure generates a large number of trades with low variance and small but negative returns (because of transaction costs). These trades are initiated when fitting errors of the parametric yield curve produces false-positive signals. ${ }^{11}$ These trades are liquidated when the fitting errors are reversed. Panels (C) and (D) show the contour map for trades using relative value in the long and short sample, respectively. By contrast with the noise measure, the results show that relative value does not generate this type of false-positive signal. Most trades have positive returns and higher variance.

\subsection{Mean and Variance in the Cross-Section of Trades}

Panel (A) of Table 2 provides summary statistics in the cross-section of total returns across individual trades, reported in weekly percentage terms. The results show that trades implemented using relative value generate higher returns than trades implemented using the noise measure. The median confirms that the typical trade implemented with the noise measure has a small negative return. But the crosssectional distribution is very wide: the standard deviation is $7.4 \%$ for relative value trade and $17.2 \%$ for noise trades. These statistics are consistent with the visual representation in Figure 4.

We perform the following exercise to confirm that noise trades perform poorly owing to fitting errors of the parametric yield curve model. These errors occur when the yield curve does not fit a number of neighbouring bonds. The noise measure for these bonds may be large, but the valuation of these bonds is consistent with the

\footnotetext{
${ }^{11}$ Parametric yield curve models are built on the assumption that mispricing is absent. The curve's parameters are estimated in order to minimize the fitting errors between the curve and the bond prices used as inputs. For a more thorough discussion, see Bolder and Gusba (2002).
} 
absence of arbitrage. These are type-I false-positive errors, where the expected profit is small or negative. To confirm this hypothesis, we construct another portfolio that includes only trades where the difference between the yield of a target bond and its replicating portfolio exceeds 5 bps. We use the label "filtered" to distinguish this new portfolio of noise trades, with "unfiltered" referring to the original specification. This filter identifies trades that have a similar economic value to those identified by relative value, albeit in significantly smaller numbers.

Panel (A) of Table 2 also reports cross-sectional statistics for the noise trade, once we impose the additional filter removing type-I errors. This filter removes a large number of false-positive signals generating trades with low variance and negative returns, making the average trade more profitable. However, the cross-sectional variance increases even more. This confirms that the mass of trades with small negative ex-post returns and low variance in Figure (A) also had small expected profits (ex-ante). Strikingly, almost half of the trades $(2,249$ out of 5,957) are discarded based on this filter. In other words, the noise measure includes a large amount of statistical noise that has little or no economic value.

\subsection{Cumulative Returns}

Panel (B) of Table 2 reports the summary statistics of the time series of index returns, in monthly percentage terms. In the time series, the passage from the cross-section of trades to the index portfolio returns of trades depends on the correlations between trades. Yet, the core message does not change. Using the noise measure produces much lower returns than using relative value, unless we filter the noise measure to remove false-positive signals. The monthly returns of the portfolio of trades based on relative value and unfiltered noise measures are on average $0.52 \%$ and $0.16 \%$, respectively. This translates to average annualized returns of $6.5 \%$ and $1 \%$. This 
difference largely disappears once we impose the additional filter for false-positives. To show this, Figure 5 reports the cumulative index returns for each portfolio in the long and short sample in Panel (A) and Panel (B), respectively. The unfiltered noise signals have little economic value, with cumulative returns that are dominated by those of the other two trade portfolios. The filtered noise signal exhibits a small advantage over relative value trades early in the sample, but falls behind starting around the 2008 crisis.

Figure 6 reports the number of trades that are active over time when following different strategies. Panel (A) shows that the number of active trades is roughly the same using either relative value or the noise measure. However, Panel (B) shows that the number of trades can differ significantly when using filtered noise signals; for instance, around 1990-1994 and around 1998-2004. But the difference is particularly startling after 2010. The number of unfiltered noise trades is similar to the number of relative value trades during this period, but once the filter is applied the number of active trades drops significantly. A potential explanation for this result is the low level of bond yields and the smallness of the slope of the yield curve, which may lead parametric curve models to generate more fitting errors.

\subsection{International Trading Performance}

In this section, we compare the economic value of the relative value and noise signal for sovereign bond markets in the US, UK, Canada, Germany, France, Italy, Switzerland and Japan. The data cover the period between January 2005 and March 2017. Table 3 reports summary cross-sectional statistics for total returns across individual trades in weekly percentage terms. Relative value trades have higher median and higher average returns than noise trades in all countries except Switzerland. ${ }^{12}$ For the US,

\footnotetext{
${ }^{12}$ Unreported results show the noise signal performs well in Switzerland precisely because it does not generate a large number of trades with small negative returns and small variance. Switzerland
} 
Panels (B)-(D) in Figure 4 report the contour map of returns and volatility in the 2005-2016 sample. Again, imposing the additional filter produces noise trades with average or median returns close to or even higher than relative value trades. However, this excludes between one-third and two-thirds of trades depending on the country. This is an important result. For all these countries, the noise measure includes a large amount of statistical noise that has little or no economic value.

Table 4 reports summary statistics for the time series of index returns in different countries, reported in monthly percentage terms. The relative value strategy outperforms the unfiltered noise strategy in all countries except for Switzerland. The difference in average monthly returns ranges from $0.3 \%$ to $0.7 \%$. As expected, imposing the additional filter raises the returns from the noise strategy but, in almost all cases, this is not enough to outperform the relative value strategy. Overall, the results confirm that using relative value identifies economically meaningful price deviations, but that using the noise measure generates a large share of false-positive signals.

\section{International Relative Value Indices}

We aggregate relative values to construct an index of the dispersion of yields across bonds issued by a given entity. For international comparisons, we compute relative value indices using daily data between 2005 and 2016 for bonds issued by Canada, France, Germany, Italy, Japan, Switzerland, the UK and the US. Although not included in this analysis, the US and Canadian indices are also available from 1987 and 1994, respectively. These indices are available and updated regularly on the Bank of Canada's website.

The relative value index's construction is similar to that of HPW's noise index.

has a much smaller number of bond issues populating the yield curve. Together, this suggests that the parametric curve performs well in that country. 
The relative value index $r v_{t}$ is given by the root mean square of the individual relative values $r v_{b t}$ :

$$
r v_{t}=\sqrt{\frac{1}{N_{t}} \sum_{b=1}^{N_{t}} r v_{b t}^{2}},
$$

where $N_{t}$ is the number of outstanding securities of the same issuer and with a remaining time to maturity of between 1 and 10 years at time $t$. When computing the dispersion index, we exclude bonds with a relative value greater than four times the sample standard deviation. HPW implements the same filter.

\subsection{Commonality}

We check that individual relative values are highly correlated within each country. Table 5 reports the share of variations explained by the first two principal components in each country. ${ }^{13}$ Across countries, the first two principal components explain between $40 \%$ and $80 \%$ of the variations, justifying the construction of a relative value index for each country.

Table 6 reports the correlations between the relative value indices of each country. Indeed, the indices for Germany, Switzerland, the UK and Canada are all correlated with the US dispersion index (the correlations range between 0.4 and 0.9 ). On the other hand, the indices for Italy and France are correlated with each other but not with the indices of other countries. Panel (A) of Figure 7 reports the relative value indices for Canada, Germany, Switzerland, the US and the UK. As expected, the relative value indices exhibit very similar patterns: a calm period with low relative value before 2007, followed by a gradual increase starting in 2007 with a dramatic peak in 2009, and with a gradual moderation since the end of the crisis. The correlation of

\footnotetext{
${ }^{13}$ We compute the principal components using balanced panels of relative value observations. To construct a balanced panel, we fix the number of bonds in the panel to the first percentile of the number of outstanding bonds throughout the sample for each country. Every day we populate the panel with the bonds with the longest remaining time to maturity, as long as it is under 10 years. The results are robust to other specifications.
} 
the US index is 0.86 with the UK index and 0.48 with Canada's index. This pattern suggests that the limits of arbitrage are largely common for these large advanced economies' sovereign issuers.

Panel (B) of Figure 7 compares the relative value indices of France and Italy. The index for Italy exhibits a striking peak at the height of the euro area sovereign debt crisis. The index for France also increases during that period. Finally, the relative value index for Japan appears to be largely idiosyncratic (Panel C)

\subsection{Relative Value, Funding Costs and Volatility}

The relative value index should be correlated with a local proxy for volatility. Figure 8 shows that the relative value indices in the US, UK, Germany and Canada are strongly related with the equity market volatility index in each country. This is consistent with arbitrage capital becoming scarcer when financial markets are more volatile in each country. Table 7 shows the correlations with local and US market volatility. We use the VIX for equity market volatility in the US, the Euro Stoxx 50 Volatility Index (VSTOXX) for euro area countries, the FTSE 100 Volatility Index (VFTSE) for the UK, and the Nikkei Volatility Index (VNKY) for Japan. These volatility indices are forward-looking. The correlations are very high except for France and Italy, perhaps because the relative value indices in these countries were not reflected in the euro areawide market volatility VSTOXX. Table 7 also shows the correlations of the relative value indices in each country with local and US interbank-OIS spreads. Again, the correlations are high, except for France and Italy. 


\section{Conclusion}

We introduce the relative value measure of limits of arbitrage in fixed-income markets. Relative value measures deviations of a bond's value relative to other similar bonds. In contrast to existing approaches, relative value does not require the estimation of a parametric model. This offers several benefits. Relative value can be computed quickly, while parametric methods require non-linear optimization using many bonds. Relative value requires only a few bonds to compute, while parametric models require a large sample of bonds. Relative value emphasizes price deviations that are economically significant, whereas parametric models produce results that are polluted by fitting errors.

We apply our framework to several sovereign bond issuers. We use the case of the US Treasury bond market to compare relative value with the existing parametric noise measure. We show that relative value produces signals that have greater economic value on average. Between one-third and two-thirds of signals generated by the noise

measure have little or no economic value. They tend to capture fitting errors that are reversed over time as the estimated curve changes, instead of price deviations that emerge and reverse over time because of arbitrage activities.

Extending the analysis to several other countries, we find that the relative value index is correlated with local equity market volatility indices and domestic interbank lending market conditions. In addition, the relative value indices exhibit a large degree of commonality across countries. These relative value indices are available publicly and will be regularly updated. We hope that these indices will help to answer a number of research questions. In addition, future research could apply our methodology to create relative value indices for supranational, sub-national or corporate bond markets. 


\section{References}

Amihud, Y. and H. Mendelson (1991). Liquidity, maturity and the yields on U.S. Treasury securities. Journal of Finance 46, 1411-1425.

Bliss, R. R. (1996). Testing term structure estimation methods. Working paper 96-12a, Federal Reserve Bank of Atlanta.

Bolder, D. and S. Gusba (2002). Exponentials, polynomials, and Fourier series: More yield curve modelling at the Bank of Canada. Bank of Canada Staff Working Paper No. 2002-29.

Duarte, J., F. A. Longstaff, and F. Yu (2007). Risk and return in fixed-income arbitrage: Nickels in front of a steamroller? Review of Financial Studies 20(3), 769-811.

Duffie, D. (1996). Special repo rates. The Journal of Finance 51(2), 493-526.

Fontaine, J. and R. Garcia (2012). Bond liquidity premia. Review of Financial Studies 25(4), $1207-1254$.

Fontaine, J. and R. Garcia (2015). Handbook of Fixed Income, Chapter Recent Advances in Old Fixed-Income Topics: Liquidity, Learning, and the Lower Bound.

Green, R. C. and B. A. Ødegaard (1997). Are there tax effects in the relative pricing of US government bonds? The Journal of Finance 52(2), 609-633.

Grkaynak, R., B. Sack, and J. H. Wright (2007). The US Treasury yield curve: 1961 to the present. Journal of Monetary Economics 54(8), 2291-2304.

Liu, J. and F. A. Longstaff (2004). Losing money on arbitrage: Optimal dynamic portfolio choice in markets with arbitrage opportunities. Review of Financial Studies 17(3), 611641.

Longstaff, F. (2004). The flight-to-liquidity premium in US Treasury bond prices. The Journal of Business $77(3), 511-526$.

Malkhozov, A., P. Mueller, A. Vedolin, and G. Venter (2016). International illiquidity. Working paper, London School of Economics.

Ron, U. (2000). A practical guide to swap curve construction. Bank of Canada Staff Working Paper No. 2000-17.

Svensson, L. E. (1994). Estimating and interpreting forward interest rates: Sweden 19921994. Working Paper 4871, National Bureau of Economic Research.

Vayanos, D. and J. L. Vila (2009). A preferred-habitat model of the term structure of interest rates. Working Paper 15487, National Bureau of Economic Research.

Vayanos, D. and P.-O. Weill (2008). A search-based theory of the on-the-run phenomenon. The Journal of Finance 63(3), 1361-1398. 


\section{A Appendix}

\section{A.1 Data Filter}

For each country, we include all bullet government bonds with a remaining term to maturity between 1 and 10 years. To calculate the relative value measure for the shortest or longest maturity bonds, we rely on bonds and bills slightly outside that range. We exclude days where fewer than 4 bonds report a yield. We also exclude inflation-linked bonds, callable bonds, fungible bonds, strips, perpetual bonds (UK), retail bonds (Japan) and flower bonds (US).

We also exclude outliers using the following filters:

- We correct for errors in the reported yields of a bond. Every day for every bond, we calculate the median level of mid yields for the 6 bonds with the nearest remaining term to maturity, as well as the absolute median deviation from this median. If the reported mid yield of the bond is larger than 5 bps from the median level and 6 times the median absolute deviation, we recalculate the bid, ask and mid yields to maturity using the quoted price and replace their original values if the new values fall within the thresholds.

- We correct for errors in the bid-ask spread. Every day for every bond, we filter for bonds with a bid-ask spread of more than 30 bps, a bid-ask spread greater than $\$ 1$ per $\$ 100$ of par value or a negative bid-ask spread in terms of yields or price. For bonds breaching one of these thresholds, we calculate the median level of bid and ask yields for the 6 bonds with the nearest remaining term to maturity, as well as the absolute median deviation from this median. We identify if the bid or ask yields are breaching the thresholds of 5 bps from the median level and 6 times the median absolute deviation. If both bid and ask prices and yields breach the thresholds, we drop the observation. If only the bid (ask) yield is breaching the threshold, we replace the bid (ask) yield and price by the ask (bid) yield plus (minus) the median bid-ask spread of the neighbouring 6 bonds; we also replace the bid (ask) price by the ask (bid) price minus (plus) the median bid-ask spread of the neighbouring 6 bonds.

- We filter for obvious outliers in yields. Every day for every bond curve, we filter for obvious outliers in terms of yields or bid-ask spread. First, we calculate a polynomial curve using all active bonds with greater than 200 days remaining until maturity. This curve is calculated with a constant, the remaining time to maturity and the square of the remaining time to maturity of every bond as the regressors and observed median yields to maturity of every bond as the regressands. We calculate the 90th percentile of absolute regression residuals. Bonds breach the threshold if the absolute difference between the curve-implied and observed yield to maturity is more than twice the 90th percentile of regression residuals and that the yield to maturity is more than 50 bps from the median level of yields of the 4 bonds with the closest term to maturity. We exclude these observations. Second, we filter for bonds whose quoted yield bid-ask spread is more than 6 times the 90th bid-ask spread of active bonds with more than 200 days remaining until maturity, as long as this bid-ask spread exceeds 10 bps. We exclude these observations. 
Figure 1: Dispersion of US Treasury Yields to Maturity

Yields to maturity for US Treasury securities from the CRSP database plotted against each security's duration. The Grkaynak et al. (2007) parametric par curve (GSW) is plotted for comparison.

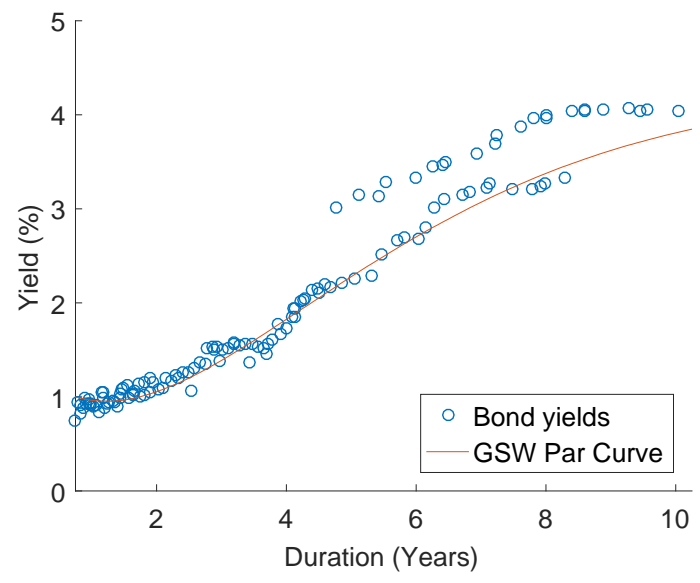

(A) 24 November 2008

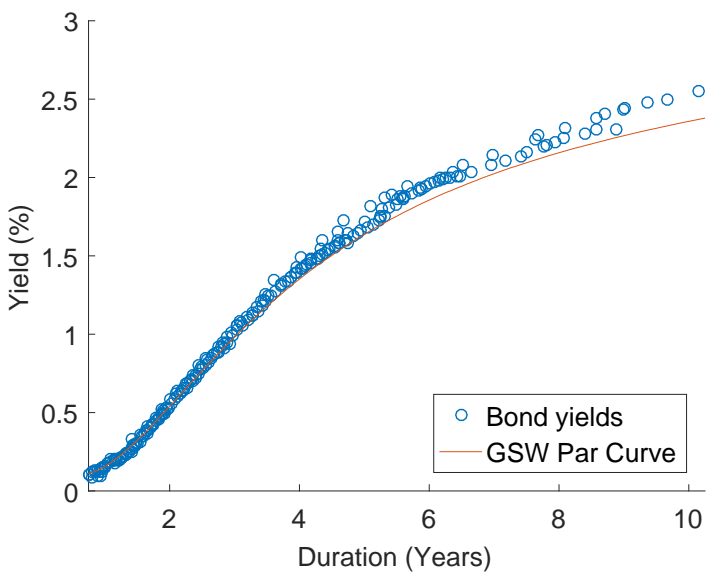

(B) 24 November 2014

Figure 2: Persistence and Duration of Trading Signals in the US (1988-2017)

Panel A: histogram of $\mathrm{AR}(1)$ parameters estimated from the time series of each bond's relative value and noise measures, respectively. Panel B: histogram of the number of days between the implementation and liquidation of every trade based on the relative value and noise measures, respectively.

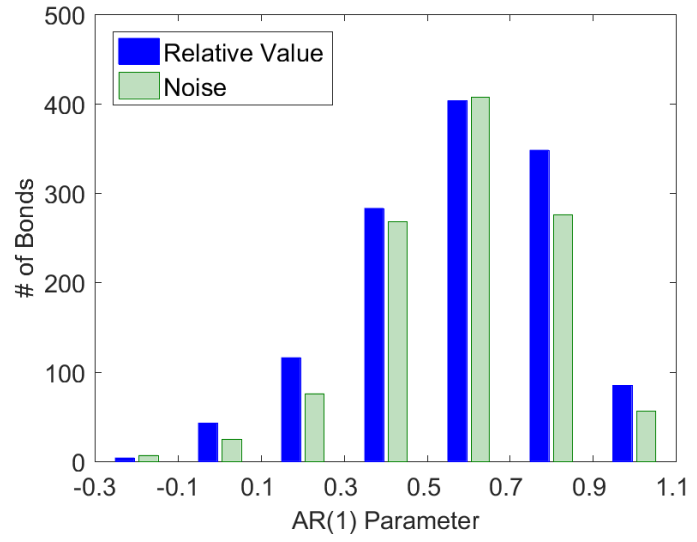

(A) Persistence

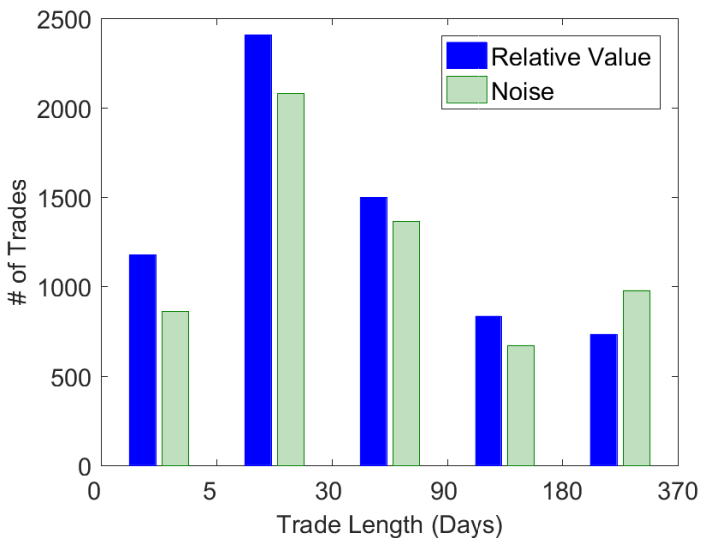

(B) Duration 
Figure 3: Distribution of Profits and Volatility in the US (1988-2017)

Panel A: histogram of total profits or losses of every trade based on the relative value or noise measures, respectively. Panel B: histogram of the volatility of daily trade returns for the relative value or the noise measure, respectively. The standard deviation of daily returns is calculated between the implementation and the liquidation of every trade.

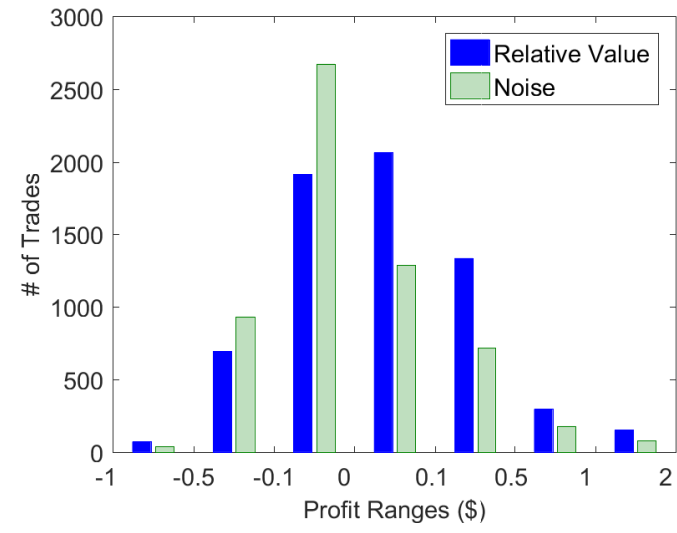

(A) Profits and Losses

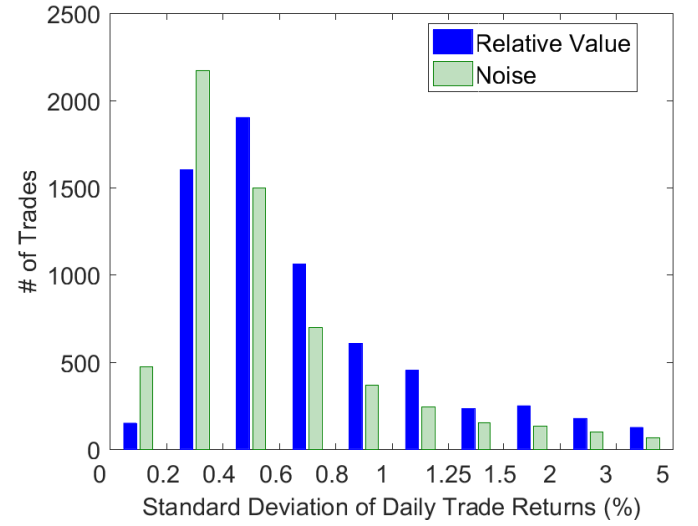

(B) Volatility 
Figure 4: Distribution of Trade Returns in the US

Contour maps of the number of trades for different values of the mean and standard deviation of daily trade returns. The mean and standard deviation are calculated between the implementation and liquidation of each trade.

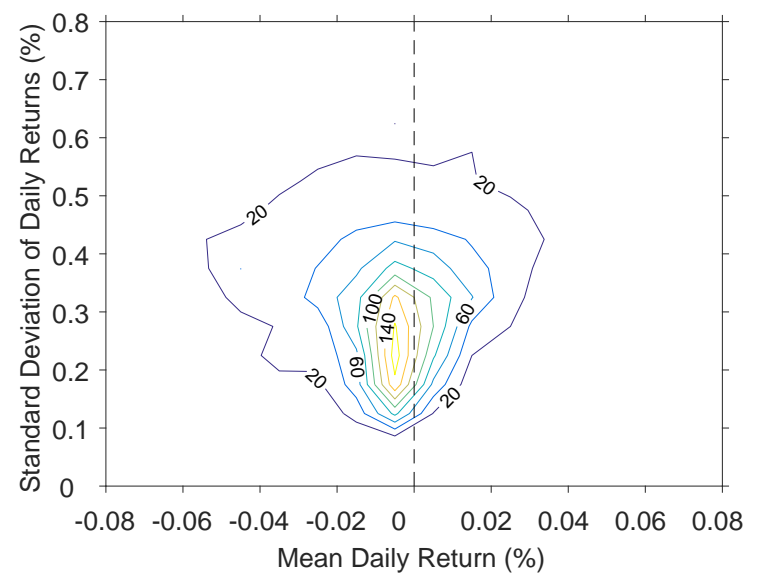

(A) Noise Measure (1988-2017)

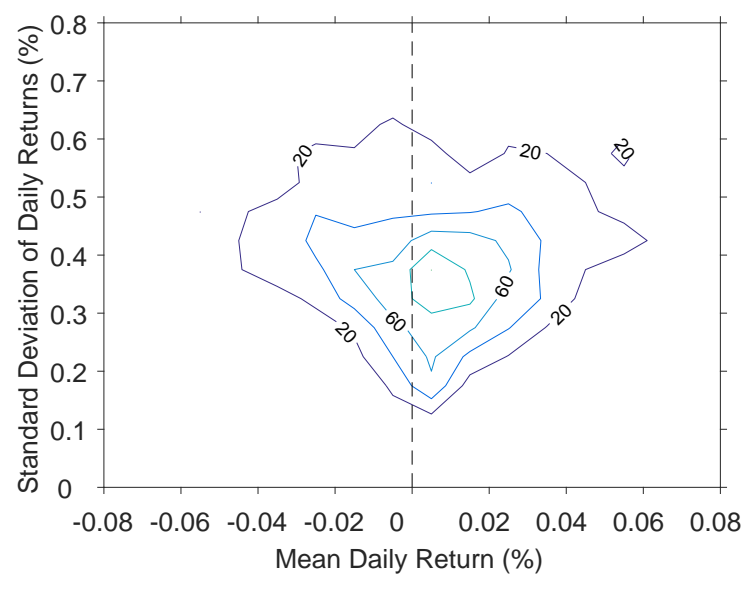

(C) Relative Value (1988-2017)

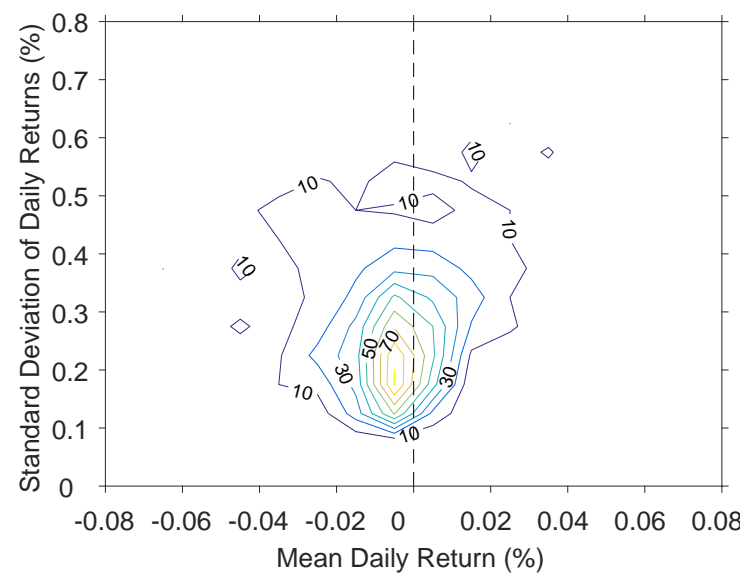

(B) Noise Measure (2005-2017)

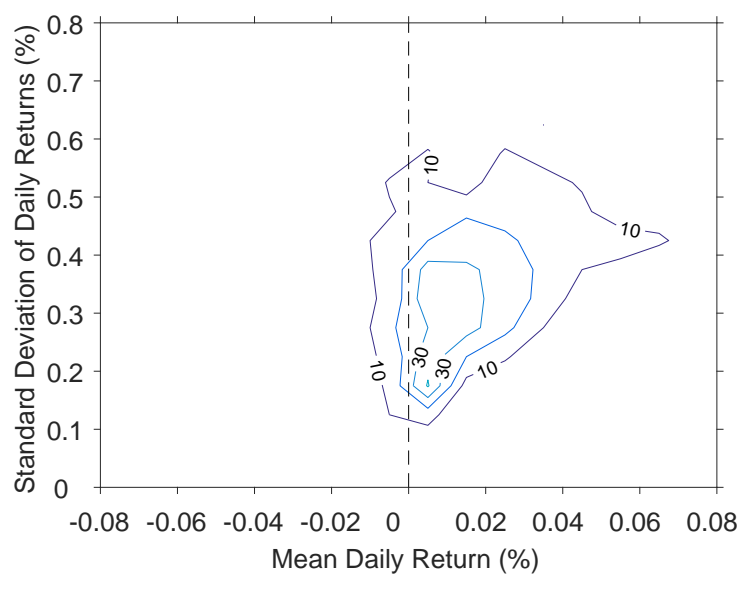

(D) Relative Value (2005-2017) 
Figure 5: Cumulative Portfolio Returns in the US (1988-2017)

Cumulative returns for the indices of equally weighted portfolios of trades generated using relative value, unfiltered noise and filtered noise measures, respectively. The indices are set to 100 on January 1st, 1988.

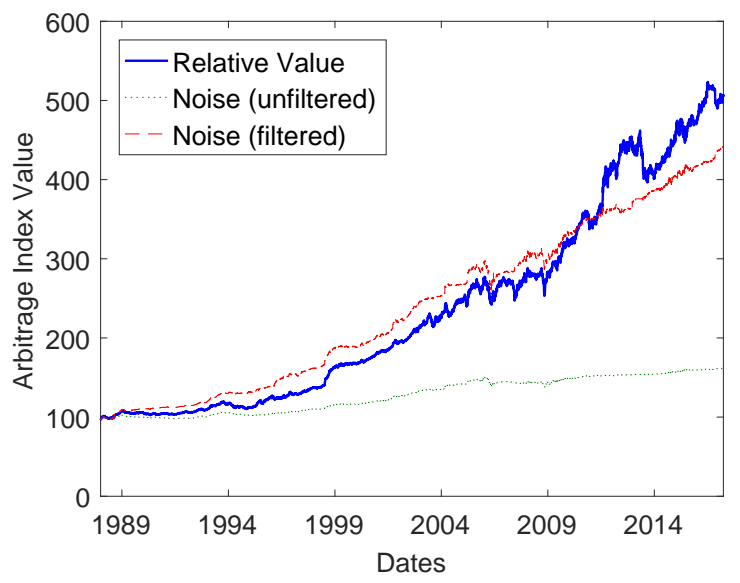

(A) US (1988-2017)

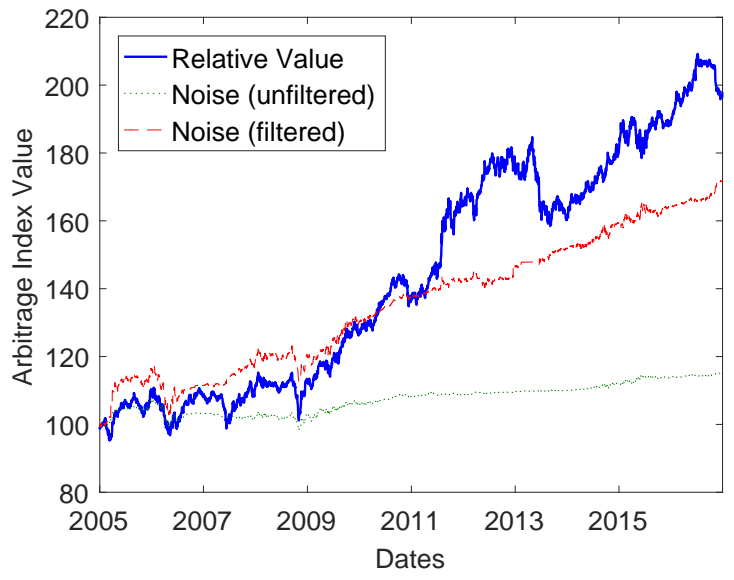

(B) US (2005-2017)

Figure 6: Number of Trades in the US (1988-2017)

Number of outstanding trades generated by the relative value and the noise measure (Panel A) or the filtered noise measure (Panel B), respectively.

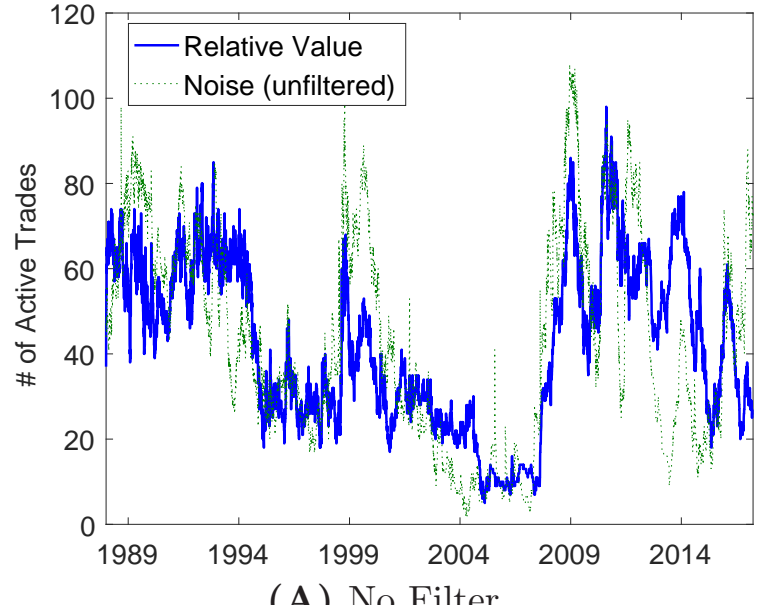

(A) No Filter

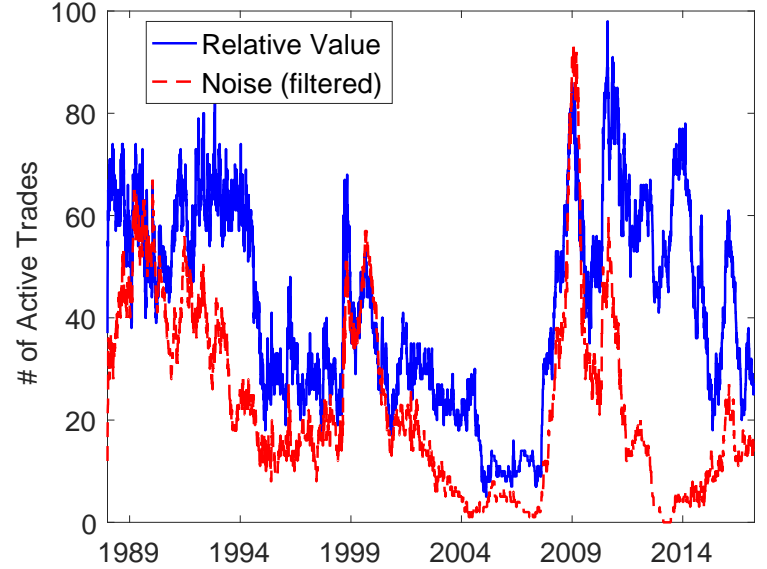

(B) Filter 


\section{Figure 7: International Relative Value Indices}

Aggregate relative value indices for sovereign issuers in different advanced economies. The figures are computed daily using end-of-day yields for bonds with between 1 and 10 years remaining until maturity.

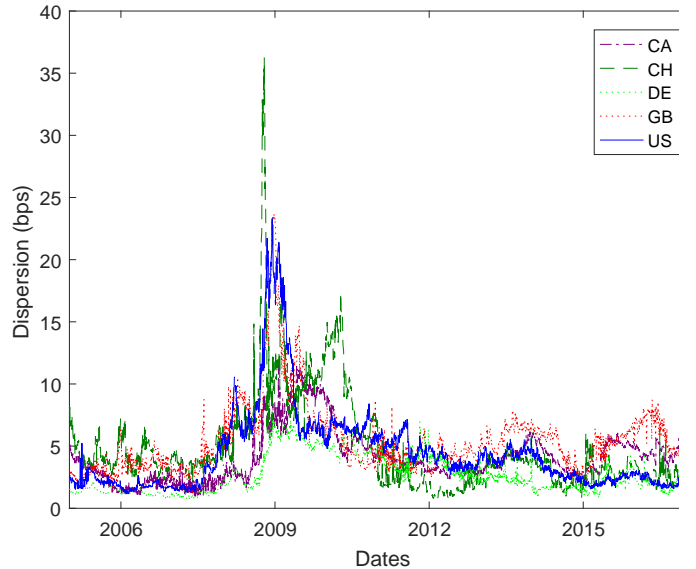

(A) US, UK, Canada, Germany and Switzerland

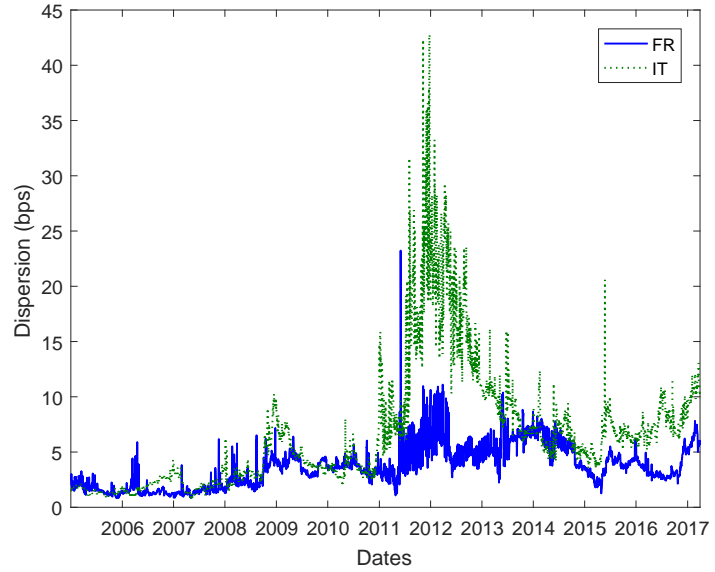

(B) France and Italy

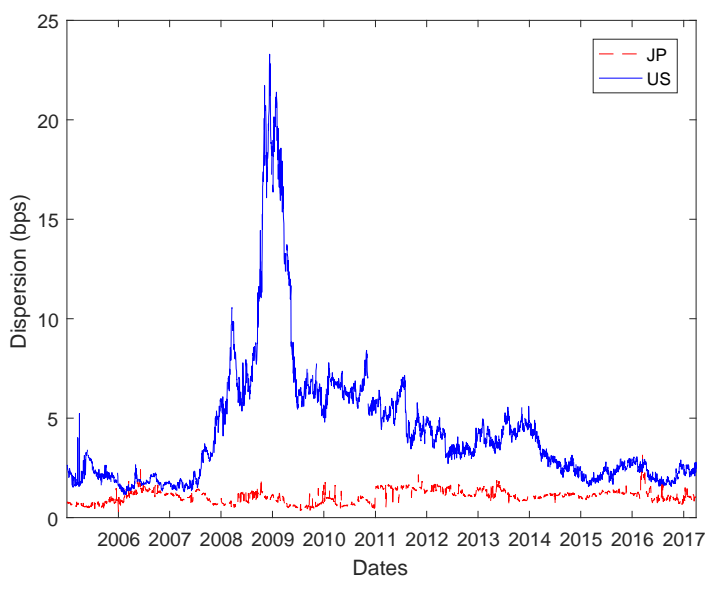

(C) Japan and US 
Figure 8: Relative Value Index and Volatility

Comparison of the sovereign issuer's relative value index and the local stock market volatility index. Daily values.
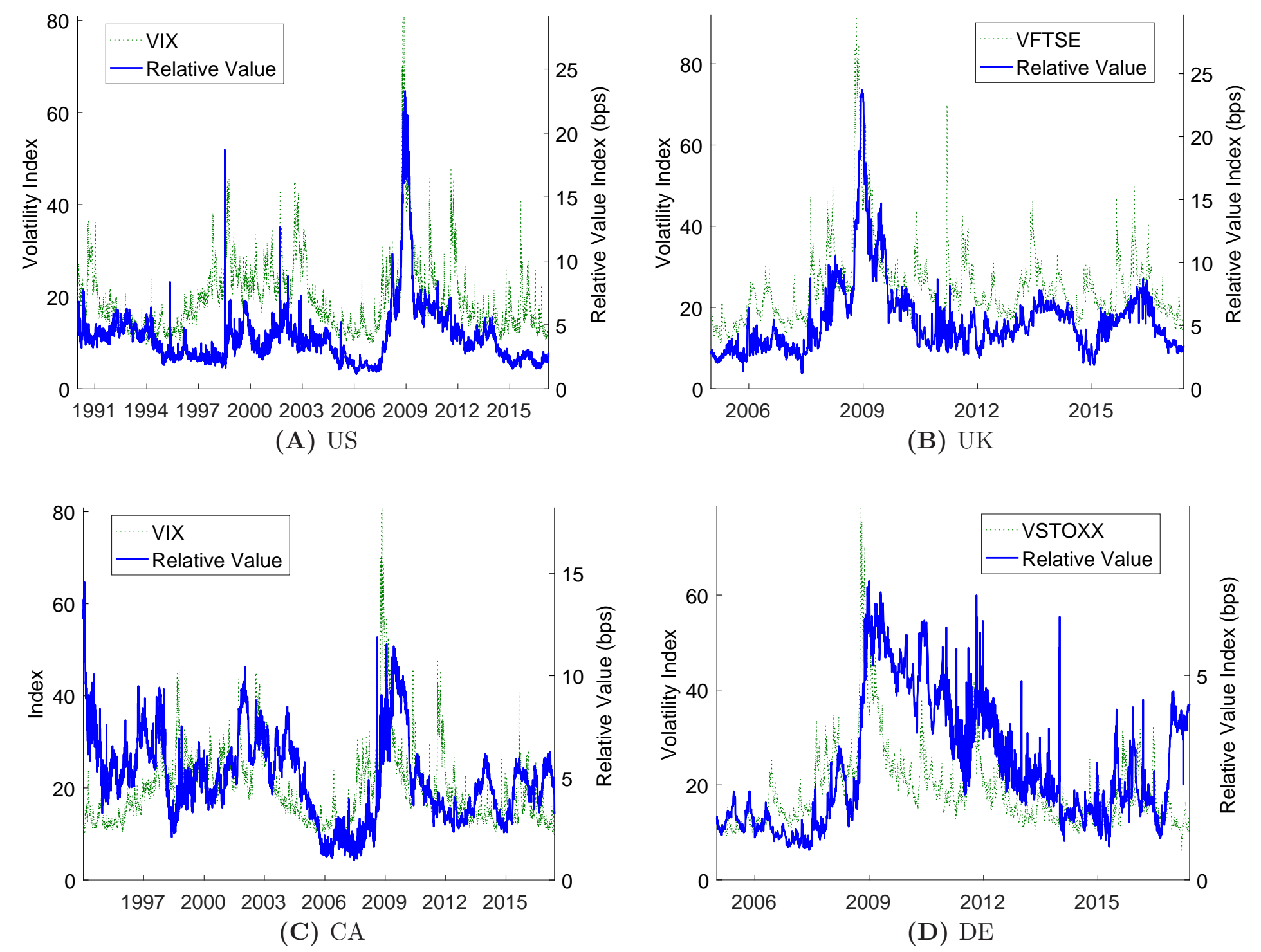
Table 1: Summary Statistics for Sovereign Issuers

Summary statistics by sovereign issuer. Sample period is 1987-2017 for the US, 1994-2017 for Canada, and 2005-2017 for other countries.

\begin{tabular}{lrrrrrrrr}
\hline & US & GB & CA & CH & DE & FR & IT & JP \\
\cline { 2 - 7 } \# Obs. & 462605.00 & 56356.00 & 88571.00 & 33811.00 & 109137.00 & 79626.00 & 120932.00 & 447604.00 \\
\# Bonds, Median & 159.00 & 18.00 & 29.00 & 11.00 & 35.00 & 29.00 & 40.00 & 139.00 \\
\# Bonds, 25th Perc. & 102.00 & 16.00 & 26.00 & 10.00 & 28.00 & 17.00 & 25.00 & 131.00 \\
\# Bonds, 75th Perc. & 202.00 & 19.00 & 30.00 & 11.00 & 39.00 & 31.00 & 50.00 & 146.00 \\
Avg. Duration & 3.62 & 4.27 & 3.55 & 4.93 & 4.16 & 4.51 & 3.91 & 4.37 \\
Avg. Std. Dev. of Duration & 1.91 & 2.03 & 1.95 & 2.23 & 2.20 & 2.17 & 2.09 & 2.42 \\
Avg. Coupon & 3.39 & 4.91 & 4.80 & 2.97 & 3.21 & 4.00 & 3.85 & 1.33 \\
Avg. Std. Dev. of Coupon & 2.00 & 1.95 & 2.90 & 0.86 & 1.17 & 1.75 & 1.30 & 0.86 \\
\hline
\end{tabular}

Table 2: Returns Summary Statistics for US Treasuries (1988-2017)

Panel (A): summary statistics for the cross-section of total trade returns (weekly percentage terms). Panel (B): summary statistics for the time series of monthly portfolio returns, in percentage terms.

Panel (A) Cross-Section of Trade Total Returns

\begin{tabular}{llcccc}
\hline & & Mean & Median & Std. Dev. & \# Trades \\
\cline { 3 - 6 } & & 0.88 & 0.03 & 7.44 & 6650 \\
US & Nolative Value (unfiltered) & 0.55 & -0.02 & 17.18 & 5957 \\
& Noise (filtered) & 1.65 & 0.03 & 25.46 & 2708 \\
\hline
\end{tabular}

Panel (B) Time Series of Portfolio Returns

\begin{tabular}{llcccccc}
\hline \multirow{4}{*}{ US } & Relative Value & 0.52 & Std. Dev. & Min & Max & Skew & Kurt \\
\cline { 2 - 7 } & Noise (unfiltered) & 0.16 & 0.62 & -3.44 & 2.94 & -0.33 & 10.53 \\
& Noise (filtered) & 0.46 & 1.07 & 5.75 & 6.37 & -0.00 & 11.30 \\
\hline
\end{tabular}


Table 3: Summary Statistics - Cross-Section of Trade Returns for All Countries (2005-2017) Mean, median and standard deviation in the cross-section of trade returns, from implementation to liquidation. Weekly returns, in percentage terms.

\begin{tabular}{|c|c|c|c|c|c|}
\hline \multirow{4}{*}{ US } & & Mean & Median & Std. Dev. & \# Trades \\
\hline & Relative Value & 0.46 & 0.09 & 3.19 & 2231 \\
\hline & Noise (unfiltered) & 0.02 & -0.01 & 1.71 & 2281 \\
\hline & Noise (filtered) & 0.36 & 0.04 & 2.53 & 871 \\
\hline \multirow{3}{*}{ UK } & Relative Value & 1.09 & 0.14 & 3.08 & 343 \\
\hline & Noise (unfiltered) & 1 & 0.14 & 2.9 & 229 \\
\hline & Noise (filtered) & 0.83 & 0.14 & 1.94 & 173 \\
\hline \multirow{3}{*}{$\mathrm{CA}$} & Relative Value & 0.55 & 0.04 & 3.19 & 244 \\
\hline & Noise (unfiltered) & -0.07 & -0.03 & 1.78 & 300 \\
\hline & Noise (filtered) & 1.09 & 0.06 & 3.98 & 102 \\
\hline \multirow{3}{*}{$\mathrm{DE}$} & Relative Value & 2.93 & 0.27 & 7.86 & 400 \\
\hline & Noise (unfiltered) & 3.84 & 0.12 & 10.08 & 298 \\
\hline & Noise (filtered) & 5.67 & 0.83 & 11.99 & 195 \\
\hline \multirow{3}{*}{$\mathrm{CH}$} & Relative Value & 1.24 & 0.13 & 5.56 & 112 \\
\hline & Noise (unfiltered) & 1.16 & 0.24 & 4.79 & 126 \\
\hline & Noise (filtered) & 2.17 & 0.46 & 5.5 & 78 \\
\hline \multirow{3}{*}{ FR } & Relative Value & 4.23 & 0.23 & 17.94 & 461 \\
\hline & Noise (unfiltered) & 6.49 & 0.47 & 17.29 & 394 \\
\hline & Noise (filtered) & 10.66 & 1.71 & 20.78 & 222 \\
\hline \multirow{3}{*}{ IT } & Relative Value & 5.99 & 0.62 & 27.85 & 2257 \\
\hline & Noise (unfiltered) & 2.75 & 0.18 & 16.13 & 1824 \\
\hline & Noise (filtered) & 5.96 & 0.54 & 19.75 & 1261 \\
\hline \multirow{3}{*}{ JP } & Relative Value & 0.62 & 0.07 & 3.96 & 417 \\
\hline & Noise (unfiltered) & 0.34 & 0.05 & 2.34 & 543 \\
\hline & Noise (filtered) & 0.38 & 0.07 & 2.94 & 162 \\
\hline
\end{tabular}


Table 4: Summary Statistics-Monthly Index Returns (2005-2017) Summary statistics for the time series of monthly portfolio returns, in percentage terms.

\begin{tabular}{|c|c|c|c|c|c|c|c|}
\hline \multirow{4}{*}{ US } & \multirow{4}{*}{$\begin{array}{l}\text { Relative Value } \\
\text { Noise (unfiltered) } \\
\text { Noise (filtered) }\end{array}$} & \multirow{3}{*}{$\begin{array}{c}\text { Mean } \\
0.54 \\
0.12\end{array}$} & \multirow{2}{*}{$\frac{\text { Std. Dev. }}{2.30}$} & \multirow{2}{*}{$\begin{array}{c}\text { Min } \\
-8.76\end{array}$} & \multirow{2}{*}{$\frac{\operatorname{Max}}{7.55}$} & \multirow{2}{*}{$\frac{\text { Skew }}{-0.51}$} & \multirow{2}{*}{$\begin{array}{c}\text { Kurt } \\
4.93\end{array}$} \\
\hline & & & & & & & \\
\hline & & & 0.70 & -3.44 & 2.94 & -0.94 & 12.28 \\
\hline & & 0.42 & 1.24 & -5.75 & 4.1 & -1.09 & 9.46 \\
\hline \multirow{3}{*}{ UK } & Relative Value & 0.49 & 1.50 & -4.87 & 5.25 & 0.12 & 4.93 \\
\hline & Noise (unfiltered) & 0.17 & 1.33 & -3.08 & 5.09 & 0.58 & 4.87 \\
\hline & Noise (filtered) & 0.14 & 1.46 & -4.15 & 4.76 & 0.18 & 4.64 \\
\hline \multirow{3}{*}{ CA } & Relative Value & 0.42 & 2.81 & -10.03 & 9.95 & -0.7 & 6.93 \\
\hline & Noise (unfiltered) & 0.14 & 1.51 & -7.82 & 7.05 & -0.28 & 12.19 \\
\hline & Noise (filtered) & 0.45 & 1.93 & -9.76 & 7.15 & -1.38 & 12.81 \\
\hline \multirow{3}{*}{$\mathrm{DE}$} & Relative Value & 0.94 & 2.82 & -11.06 & 14.77 & 0.03 & 11.04 \\
\hline & Noise (unfiltered) & 0.66 & 1.16 & -1.89 & 6.03 & 2.38 & 10.45 \\
\hline & Noise (filtered) & 1.21 & 2.33 & -2.55 & 14.62 & 2.98 & 13.78 \\
\hline \multirow{3}{*}{$\mathrm{CH}$} & Relative Value & 0.61 & 1.92 & -6.34 & 10.14 & 0.78 & 11.19 \\
\hline & Noise (unfiltered) & 0.64 & 2.01 & -7.41 & 9.96 & 1.56 & 10.42 \\
\hline & Noise (filtered) & 0.74 & 2.12 & -4.48 & 10.4 & 2.15 & 9.41 \\
\hline \multirow{3}{*}{ FR } & Relative Value & 2.11 & 5.11 & -10.55 & 28.49 & 2.44 & 12.89 \\
\hline & Noise (unfiltered) & 1.94 & 4.32 & -7.38 & 24.08 & 2.39 & 10.66 \\
\hline & Noise (filtered) & 3.09 & 7.14 & -4.22 & 42.12 & 2.83 & 11.93 \\
\hline \multirow{3}{*}{ IT } & Relative Value & 1.52 & 3.16 & -4.21 & 27.32 & 4.75 & 35.70 \\
\hline & Noise (unfiltered) & 0.81 & 1.72 & -8.02 & 9.15 & 0.5 & 13.41 \\
\hline & Noise (filtered) & 1.35 & 2.41 & -4.1 & 13.31 & 2.4 & 10.74 \\
\hline \multirow{3}{*}{ JP } & Relative Value & 0.49 & 1.39 & -4.07 & 7.96 & 0.96 & 9.69 \\
\hline & Noise (unfiltered) & 0.19 & 0.77 & -4.5 & 2.44 & -1.39 & 13.85 \\
\hline & Noise (filtered) & 0.21 & 1.41 & -6.81 & 8.4 & 0.77 & 16.52 \\
\hline
\end{tabular}

Table 5: Principal Components of Relative Value Measures

Share of the variations in a balanced panel of individual bonds' relative value measures explained by the first two principal components, in each country. The sample period is from 2005 to 2017.

\begin{tabular}{lrlllllrr}
\hline & US & GB & CA & CH & DE & FR & IT & JP \\
\cline { 2 - 8 } 1st & 0.29 & 0.40 & 0.23 & 0.72 & 0.26 & 0.27 & 0.31 & 0.13 \\
2nd & 0.06 & 0.15 & 0.16 & 0.11 & 0.11 & 0.16 & 0.13 & 0.06 \\
\hline
\end{tabular}


Table 6: International Relative Value Indices-Correlations

Correlation between the daily relative value indices in each country. The sample period is from 2005 to 2017.

\begin{tabular}{lrrrrrrrr}
\hline & US & GB & CA & CH & DE & FR & IT & JP \\
\cline { 2 - 9 } US & 1.00 & 0.79 & 0.53 & 0.63 & 0.68 & 0.15 & 0.04 & -0.18 \\
GB & 0.79 & 1.00 & 0.59 & 0.51 & 0.51 & 0.16 & 0.01 & -0.12 \\
CA & 0.53 & 0.59 & 1.00 & 0.56 & 0.71 & 0.29 & 0.02 & -0.32 \\
CH & 0.63 & 0.51 & 0.56 & 1.00 & 0.49 & -0.11 & -0.32 & -0.37 \\
DE & 0.68 & 0.51 & 0.71 & 0.49 & 1.00 & 0.34 & 0.28 & -0.19 \\
FR & 0.15 & 0.16 & 0.29 & -0.11 & 0.34 & 1.00 & 0.63 & 0.21 \\
IT & 0.04 & 0.01 & 0.02 & -0.32 & 0.28 & 0.63 & 1.00 & 0.44 \\
JP & -0.18 & -0.12 & -0.32 & -0.37 & -0.19 & 0.21 & 0.44 & 1.00 \\
\hline
\end{tabular}

Table 7: International Relative Value Indices, Money-Market Rates and Volatility

Correlation between the daily value of different sovereign issuers' relative value indices and local or international measures of volatility or funding stress. Local interbank rates are USD LIBOR for the US, GBP LIBOR for the UK, Canadian Dollar Offered Rate (CDOR) for Canada, CHF LIBOR for Switzerland, JPY LIBOR for Japan and Euribor for euro area countries. OIS rates are USD OIS for the US, Sterling Overnight Index Average (SONIA) for the UK, CAD OIS for Canada, CHF OIS for Switzerland, Tokyo Overnight Average Rate (TONAR) for Japan and Euro OverNight Index Average (EONIA) for euro area countries. Local volatility indices are VIX for the US, VFTSE for the UK, VNKY for Japan and VSTOXX for the euro area countries. International averages are the daily mean values for available Interbank-OIS Spreads and Volatility Indices, respectively. The sample period is from 2005 to 2017.

\begin{tabular}{lrrrrrrrr}
\hline & US & GB & CA & CH & DE & FR & IT & JP \\
\cline { 2 - 8 } 3M Local Interbank-OIS spread & 0.71 & 0.73 & 0.03 & 0.58 & 0.51 & 0.13 & 0.25 & -0.26 \\
3M US LIBOR-OIS spread & 0.71 & 0.62 & 0.26 & 0.58 & 0.31 & 0.03 & 0.06 & -0.04 \\
3M Interbank-OIS spread (intl average) & 0.31 & 0.35 & 0.03 & 0.23 & 0.00 & 0.02 & 0.07 & 0.08 \\
Volatility Index (local) & 0.82 & 0.72 & N/A & N/A & 0.51 & 0.04 & 0.11 & 0.05 \\
VIX & 0.82 & 0.66 & 0.46 & 0.57 & 0.59 & 0.09 & 0.11 & -0.08 \\
Volatility Index (intl average) & 0.76 & 0.64 & 0.40 & 0.55 & 0.51 & 0.04 & 0.11 & -0.02 \\
\hline
\end{tabular}

